\title{
The pathophysiology of endometriosis and adenomyosis: tissue injury and repair
}

\author{
G. Leyendecker $\cdot$ L. Wildt $\cdot$ G. Mall
}

Received: 23 June 2009 / Accepted: 16 July 2009 / Published online: 31 July 2009

(C) The Author(s) 2009. This article is published with open access at Springerlink.com

\begin{abstract}
Introduction This study presents a unifying concept of the pathophysiology of endometriosis and adenomyosis. In particular, a physiological model is proposed that provides a comprehensive explanation of the local production of estrogen at the level of ectopic endometrial lesions and the endometrium of women affected with the disease.

Methods In women suffering from endometriosis and adenomyosis and in normal controls, a critical analysis of uterine morphology and function was performed using immunohistochemistry, MRI, hysterosalpingoscintigraphy, videohysterosonography, molecular biology as well as clinical aspects. The relevant molecular biologic aspects were compared to those of tissue injury and repair (TIAR) mechanisms reported in literature.

Results and conclusions Circumstantial evidence suggests that endometriosis and adenomyosis are caused by trauma. In the spontaneously developing disease, chronic uterine peristaltic activity or phases of hyperperistalsis induce, at the endometrial-myometrial interface near the fundo-cornual raphe, microtraumatizations with the activation of the mechanism of 'tissue injury and repair' (TIAR). This results in
\end{abstract}

\section{G. Leyendecker $(\square)$}

Kinderwunschzentrum (Fertility Center) Darmstadt,

Bratustrasse 9, 64295 Darmstadt, Germany

e-mail: gerhard.leyendecker@t-online.de

L. Wildt

University Clinic of Gynecological Endocrinology

and Reproductive Medicine, Department of Obstetrics

and Gynecology, Medical University Innsbruck,

Anichstrasse 35, 6020 Innsbruck, Austria

G. Mall

Institute of Pathology, Klinikum Darmstadt, Academic Teaching Hospital to the Universities of Frankfurt and Heidelberg, Grafenstrasse 9, 64283 Darmstadt, Germany the local production of estrogen. With ongoing peristaltic activity, such sites might increase and the increasingly produced estrogens interfere in a paracrine fashion with the ovarian control over uterine peristaltic activity, resulting in permanent hyperperistalsis and a self-perpetuation of the disease process. Overt auto-traumatization of the uterus with dislocation of fragments of basal endometrium into the peritoneal cavity and infiltration of basal endometrium into the depth of the myometrial wall ensues. In most cases of endometriosis/adenomyosis, a causal event early in the reproductive period of life must be postulated leading rapidly to uterine hyperperistalsis. In late premenopausal adenomyosis, such an event might not have occurred. However, as indicated by the high prevalence of the disease, it appears to be unavoidable that, with time, chronic normoperistalsis throughout the reproductive period of life leads to the same extent of microtraumatization. With the activation of the TIAR mechanism followed by infiltrative growth and chronic inflammation, endometriosis/adenomyosis of the younger woman and premenopausal adenomyosis share in principle the same pathophysiology. In conclusion, endometriosis and adenomyosis result from the physiological mechanism of 'tissue injury and repair' (TIAR) involving local estrogen production in an estrogen-sensitive environment normally controlled by the ovary.

Keywords Endometriosis - Adenomyosis - Endometrial estrogen · Tissue injury and repair · Chronic inflammation

\section{Introduction}

Endometriosis is a disease that affects many women predominantly during the reproductive period of life. With the cardinal symptoms, such as pelvic pain, bleeding disorders, and 
infertility, the disease has a tremendous impact on women's well-being and health. In most of the women affected the first symptoms can be traced back to adolescence [1]. Many women, however, remain free of symptoms or exhibit only minor complaints. Moreover, in cases with the development of the disease after childbearing, the condition may remain undiagnosed. Not infrequently, at laparoscopy for tubal sterilization [2] and hysterectomy for fibroids and adenomyosis, endometriotic implants and scars, respectively, can be observed. Thus, the current estimates of prevalence are probably too low. The syndrome of dislocated basal endometrium (SDBE), a term that comprises the pathophysiological continuum of endometriosis, endometriosis in association with adenomyosis and premenopausal adenomyosis, thus appears to be a very common phenomenon [3]. We had, therefore, a decade ago, suggested that its cause or causes may be unspectacular and closely related to the physiologic process of reproduction. Trauma followed by tissue specific hyper reactive inflammatory response and repair involving specific, albeit physiological cellular, biochemical, and molecular mechanisms may be considered the major events in the development of the disease [4].

In this article, an attempt is made to extend our previous views and to elaborate a comprehensive model of the pathophysiology of endometriosis and adenomyosis. This endeavor is undertaken with the premise that all phenotypes of endometriosis share in principal the same pathophysiology and that no parallel and separate mechanisms of their development do exist. This does, however, not exclude various and different etiologies at the very onset of the disease process including iatrogenic [5], exogenous [6, 7], and hereditary [8] factors. With respect to hereditary factors they might be remote from the genuine disease process and thus not easily to disclose.

\section{The role of the uterus in the disease process}

In the understanding of the pathophysiology of endometriosis and adenomyosis a re-analysis of both, structure and function of the non-pregnant uterus turned out to be of utmost importance [4, 9-11]. With uterine peristalsis and directed (sperm) transport a novel uterine function has been discovered [12-19]. It became evident that the non-pregnant uterus is constantly active throughout the reproductive period of life and thereby, like other mechanically active organs of the body such as the skeletal and the cardiovascular systems, respectively, rather inevitably subjected to mechanical strain. Research performed over the last years has demonstrated a crucial role of mechanical strain in nor$\mathrm{mal}$ and pathological function of various tissues. Moreover, it became apparent that the molecular mechanisms associated with mechanical strain, injury, and repair displays a pattern that is quite similar in different tissues and involves the expression of the $\mathrm{P} 450$ aromatase and the local production of estrogen [20]. The sequels of tissue injury and repair, however, may become very specific depending on structure and functions of the tissues and organs involved such as tendons and cartilage in the skeletal and the intima in the cardiovascular system, respectively. This is of particular importance, when the tissue, as it is the case with the uterus, is physiologically highly estrogen sensitive and when injury is chronic in character.

There are several lines of evidence for the notion that dysfunctions of the uterus play a crucial role in the pathophysiology of endometriosis.

1. Fragments of basal endometrium were found in the menstrual effluent with a higher prevalence in women with endometriosis than in controls. On the basis of these and other findings, it was suggested that pelvic endometriosis results from the transtubal dislocation of fragments of basal endometrium [21].

2. There is a significant association of pelvic endometriosis with uterine adenomyosis in women and in the baboon with life-long infertility. In women, the reported prevalence, however, differs according to the study population chosen and to the criteria applied to the interpretation of MRI findings [22-26].

3. The uterine function of rapid and directed sperm transport into the 'dominant tube' is dysfunctional in women with endometriosis and is characterized by hyper- and dysperistalsis [27-32].

It was suggested that this uterine dysfunction in women with endometriosis and adenomyosis is a result of archimetral hyperestrogenism $[3,4,29,33]$. There are several lines of evidence that support this notion.

1. In comparison to normal controls and in contrast to peripheral blood estradiol levels are elevated in menstrual blood of women with endometriosis and adenomyosis [34].

2. The expression of the $\mathrm{P} 450$ aromatase is increased in adenomyotic tissue and in the ectopic and eutopic endometrium of women with endometriosis [35-41].

3. A highly estrogen-dependent gene, Cyr61, is up-regulated in eutopic endometrium in women with endometriosis and also in ectopic lesions as well as in experimental endometriosis [42, 43].

4. The peristaltic activity of the subendometrial myometrium can be dramatically increased by elevated peripheral levels of estradiol as they are observed during controlled ovarian hyperstimulation. The intensity of uterine peristaltic activity in women with endometriosis resembles that of women during controlled ovarian hyperstimulation although the peripheral estradiol levels are within the normal range [4, 29, 44]. 


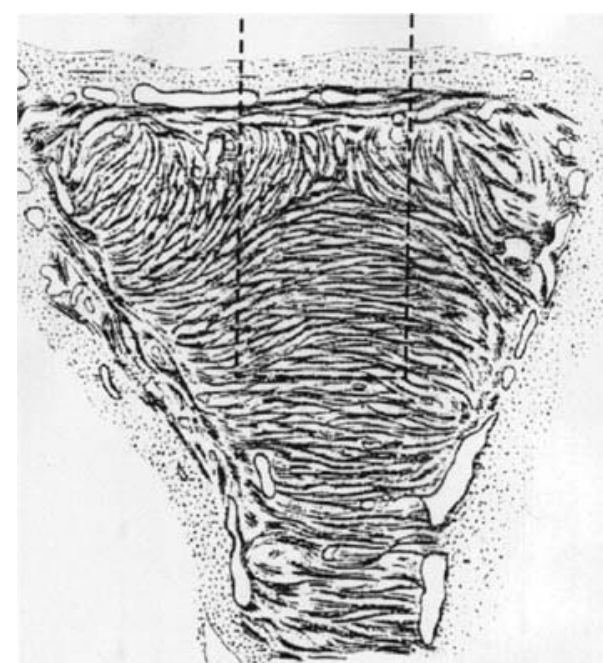

Fig. 1 Modified original drawing from Werth and Grusdew [9] showing the architecture of the subendometrial myometrium (archimyometrium) in a human fetal uterus. The specific orientation of the circular fibers of the archimyometrium results from the fusion of the two paramesonephric ducts forming a fundo-cornual raphe in the midline (dashed rectangle). The peristaltic pump of the uterus, which is continuously active during the menstrual cycle, is driven by coordinated contractions of these muscular fibers. Directed sperm transport into the dominant tube is made possible by differential activation of these fibers. The fundo-cornual raphe constitutes a region of increased mechanical strain and tissue injury followed by local estrogen production. By the time muscular distensions at the fundo-cornual raphe result in the formation of gaps that result in endometrial proliferation into these dehiscences

On the basis of the data presented above we had suggested that auto-traumatization of the uterus would constitute the critical factor in the development of endometriosis and adenomyosis [3, 4, 33]. Hyperperistalsis induced by the local production of estrogen would constitute a mechanical trauma resulting in an increased desquamation of fragments of basal endometrium and [21], in combination with an increased retrograde uterine transport capacity [29], in enhanced transtubal dissemination of these fragments. Hyperperistalsis and increased intrauterine pressure would with time, result in myometrial dehiscences that are infiltrated by basal endometrium with the secondary development of peristromal muscular tissue. Diffuse or focal adenomyosis of various extent ensue. Adenomyotic foci are usually localized in the anterior and/or posterior with preference of the posterior but only rarely in the lateral walls of the uterine corpus. Early lesions usually present close to the "fundo-cornual raphe" of the archimyometrium [3, 23, 45] (Figs. 1, 2).

\section{The enigma of archimetral hyperestrogenism}

The local production of estrogen both on the level of the eutopic endometrium in women with endometriosis and of the ectopic lesions is, undoubtedly, central to the understanding of the pathophysiology of the disease. The etiology of this increased estrogen-producing "glandular" potential of these tissues, however, is still enigmatic. It was recently suggested that the susceptibility of developing the disease with the potential to locally produce estrogen within the eutopic endometrium would be acquired by an epigenetic mechanisms during prenatal life that would become manifested not until after puberty [41]. Other authors suggest that the endometrium in women with endometriosis is inherently altered [40]. Clinical and experimental evidence do not support these views. If primary alterations of the endometrium were a prerequisite of the development of the disease it would not be possible, in the primate model, to induce peritoneal endometriosis by inoculation of endometrial fragments that were obtained from endometrial biopsies of healthy animals [43, 46-48]. Moreover, abdominal wall endometriosis following cesarean section develops in presumably primarily healthy subjects.

\section{Tissue injury and repair (TIAR)}

Recent studies have increasingly shown that estradiol is of utmost importance in the process of wound healing [4951]. This action of estrogens appears to be mainly mediated by the estrogen receptor-beta (ER2). Animal experiments with chemotoxic and mechanic stress to astroglia [20, 52, 53] and urinary bladder tissue as well as studies with isolated connective tissue such as fibroblasts and cartilage [54-56] have revealed that tissue injury and inflammation with subsequent healing is associated with a specific physiological process that involves the local production of estrogen from its precursors. Interleukin-1-induced activation of the cyclooxygenase- 2 enzyme (COX-2) results in the production of prostaglandin E2 (PGE2), which in turn activates STAR (steroidogenic acute regulatory protein) and the P450 aromatase. Thus, with the increased transport of cholesterol to the inner mitochondrial membrane testosterone can be formed and aromatized into estradiol that exerts its proliferative and healing effects via the ER2. In studies with fibroblast it was surprising that the first steps of this cascade could be activated by seemingly minor biophysical strain [54]. Following termination of unphysiological strain and healing, this process is down-regulated and the local production of estrogen or up-regulation of estrogendependent genes ceases [54, 57]. This cascade can even be activated in tissue that normally does not express the P450 aromatase indicating the basic physiological significance of the local production of estrogen in tissue injury and repair (TIAR) [58]. The similarity of the molecular biology of TIAR in various tissues with that described in 
a
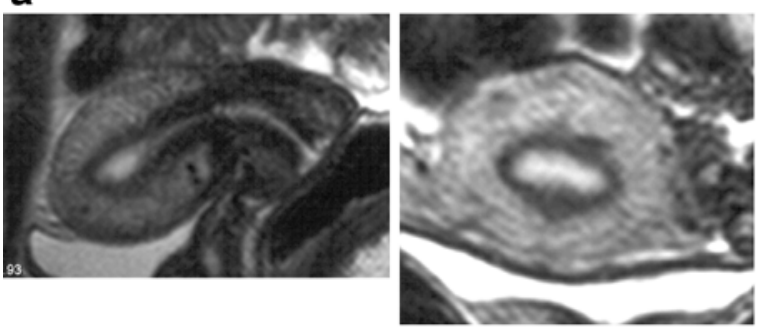

c
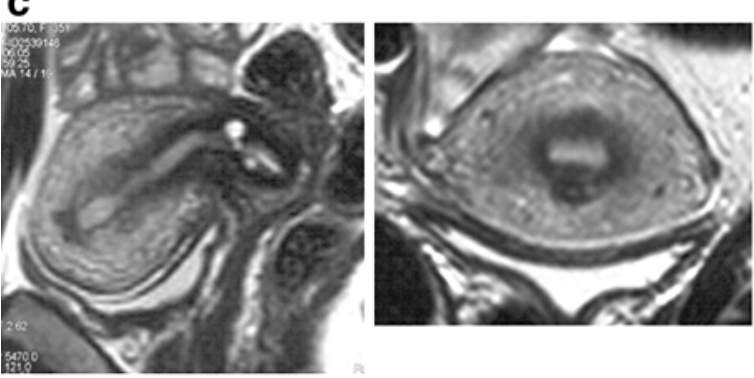

e
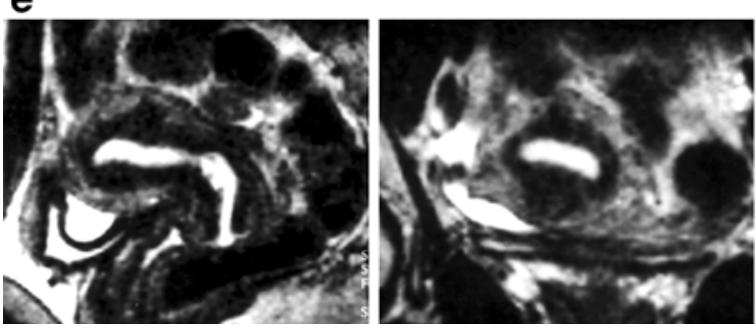

Fig. 2 Examples of uterine adenomyosis in six patients as presented by magnetic resonance imaging (MRI). Representative sagittal and coronary scans are shown. In the infertile, non-parous women $(\mathbf{a}-\mathbf{e})$ (30-32 years of age) pelvic endometriosis of grade I-IV was demonstrated by laparoscopy. In the parous woman (f) (40 years of age) no laparoscopy was performed. In all scans preponderance of the adeno-

Tissue Injury and Repair (TIAR)

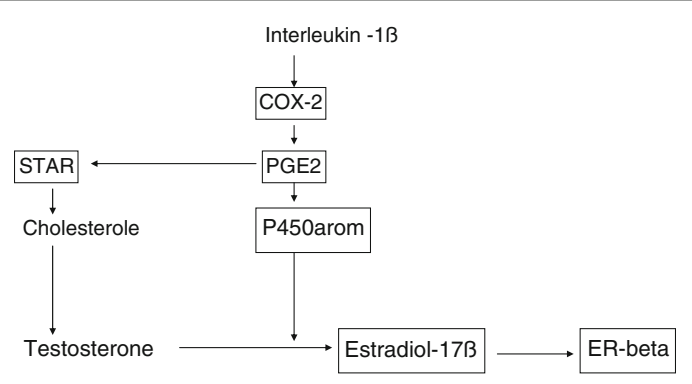

Fig. 3 The basic aspects of the molecular biology of the physiological mechanism of 'tissue injury and repair' (TIAR) as demonstrated in mesenchymal tissue such as astrocytes, tendons, and cartilage

endometriosis [39-41, 59-62] strongly suggests that this represents the common underlying mechanisms of both processes (Fig. 3).

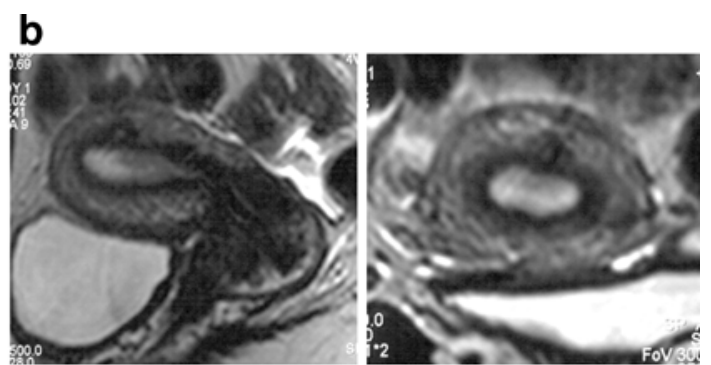

d

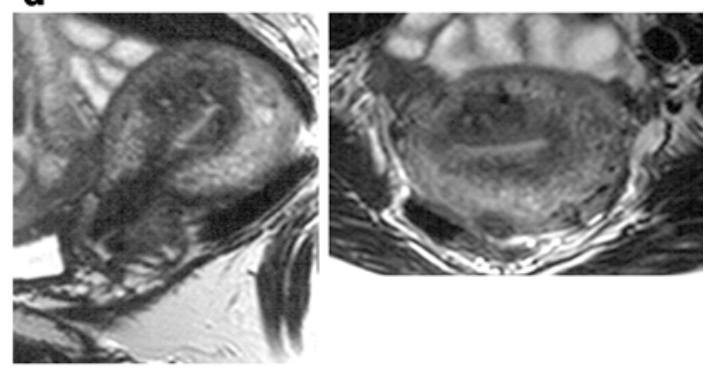

f

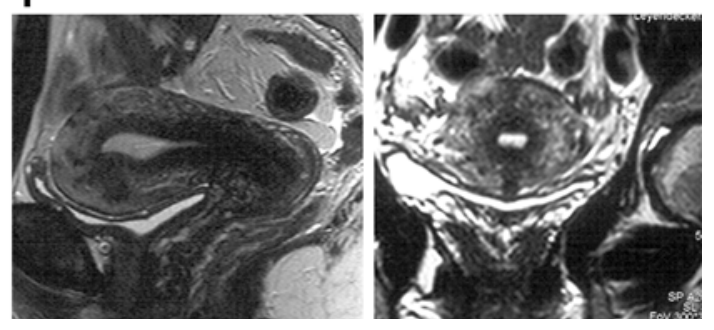

myotic lesions (expanded junctional zone) in the midline close to the fundo-cornual raphe of the archimyometrium can be demonstrated. In the first three scans $(\mathbf{a}-\mathbf{c})$ the diagnosis of adenomyosis would not meet the established radiologic criteria for MRI. In a scientific context, however, the irregularities of the junctional zone are characteristic of beginning adenomyosis

\section{Mechanism of disease: uterine auto-traumatization}

Structure and function of the subendometrial myometrium and the endocrine control of directed sperm transport have been described elsewhere $[9,15,44,45,63,64]$. It is comprehensible that the myometrial fibers and the fibroblast at the endometrial-myometrial interface near the fundo-cornual raphe are subjected to increased mechanical strain during midcycle, because not only the ovarian estradiol secretion is at its peak at that time, but also the additional mechanical strain is imposed on these cells due to estradiol that reaches the uterus via the utero-ovarian counter-current system and controls the direction of the upward transport [63]. Directed sperm transport begins during the mid-follicular phase of the cycle when the dominant follicle becomes visible [15]. The fundo-cornual raphe as a site of predilection of mechanical strain is documented by the observation that early adenomyosis usually evolves in the sagittal midline of the mid-corporal and fundal part of the uterus 
(Fig. 2). Even in more advanced cases of adenomyosis the expansion of the junctional zone in MRI often shows preponderance at these locations [3].

First step injury: microtraumatization

Experiments with cultivated fibroblasts have shown that mechanical strain within certain limits is physiological to such cells. However, even minor increments in mechanical strain resulted and the activation of COX-2 and the production of PGE2, the basic biochemical mechanisms underlying tissue injury [54], and also in the production of interleukin-8 [65]. Thus, with respect to the subendometrial myometrium, deviations from the normal cyclic endocrine pattern with increases or prolongations of estradiol stimulation of uterine peristalsis could impose supraphysiological mechanical strain on the cells near the fundo-cornual raphe. It has been attempted to relate irregularities of the menstrual cycle to the development of endometriosis without clear-cut evidence [66]. The irregularities under discussion, however, are not easily disclosed and might escape selfobservation and recording of patient history. It is tempting to speculate that events such as prolonged follicular phases, anovulatory cycles or periods of follicular persistency and also the presence of large antral follicles in both ovaries before definite selection of the dominant follicle would impose, by increased or prolonged estrogenic stimulation, stronger mechanical strain to the muscular fibers and fibroblasts. That a prolonged period of estrogenic stimulation might promote the development of endometriosis is documented in a study aiming at examining the hereditary component of endometriosis in colonized rhesus monkeys. Only a history of application of estrogen patches (in addition to a history of trauma by hysterotomy) showed a significant association with endometriosis [67]. The cyclic irregularities discussed above, that might have also a hereditary background, occur frequently during the early period of reproductive life. This concurs with an early onset of endometriosis in most cases. But also other factors should be taken into consideration that might increase the susceptibility to mechanical strain and tissue injury.

In any event, repeated and sustained overstretching and injury of the myocytes and fibroblasts at the endometrialmyometrial interface close to the fundo-cornual raphe would activate the TIAR system focally with increased local production of estradiol. This process starts on a microscopical level and complete healing might be possible particularly if the mechanical strain with subsequent tissue injury happened to be only a singular event or followed by a longer phase of uterine quiescence such as during pregnancy and breastfeeding.

During such a singular phase of 'first-step' injury, transtubal dislocation of fragments of basal endometrium might

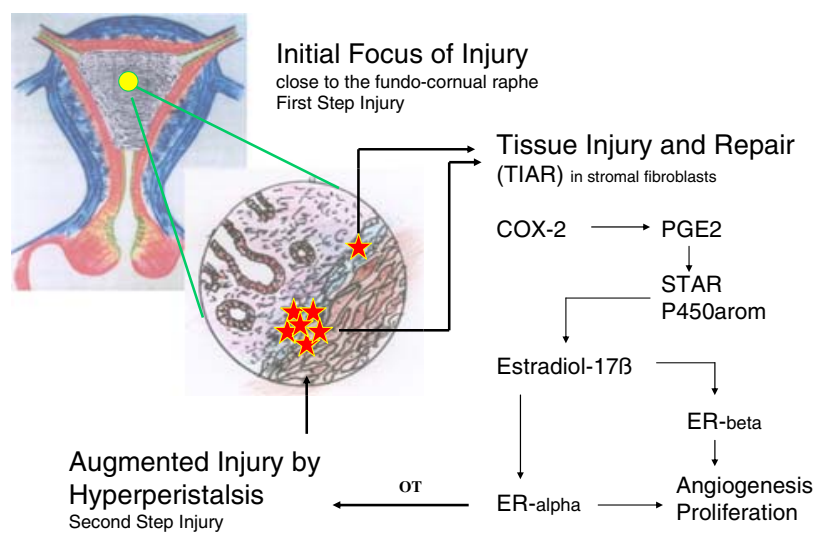

Fig. 4 Model of 'tissue injury and repair' (TIAR) on the level of the endometrial-myometrial interface at the fundo-cornual raphe. The mechanisms of first and second step injury are depicted. Persistent uterine peristaltic activity and hyperperistalsis are responsible for perpetuation of injury with permanently increased paracrine estrogen action

occur. In addition to the very low probability of transtubal seeding of fragments of the basal endometrium in normal women, such single events could contribute to the development of asymptomatic pelvic endometriosis [2, 3, 21]. In case of accidental implantation at an unfavorable site, such as the ovaries, severe intraperitoneal endometriosis could develop without further involvement of the uterus in the disease process as indicated by a completely normal junctional zone in MRI.

With continuing hyperperistaltic activity and sustained injury, however, healing at the fundo-cornual raphe will not ensue and an increasing number of foci are involved in this process of chronic injury, proliferation, and inflammation. The expansion or accumulation of such sites with an activated TIAR system renders local areas of the basal endometrium to function as an endocrine gland that produces estradiol (Fig. 4).

Second step injury: auto-traumatization by hyperperistalsis

Focal estrogen production might reach a tissue level that, in a paracrine fashion, acts upon the archimyometrium and increases uterine peristaltic activity presumably mediated by endometrial oxytocin and its receptor [44, 68, 69]. As outlined previously, hyperperistalsis causes overt uterine auto-traumatization, detachment of fragments of basal endometrium, and their transtubal dislocation into the peritoneal cavity as well as infiltrative growth of basal endometrium into the underlying myometrium resulting in pelvic endometriosis and uterine adenomyosis, respectively $[3,33]$. The latter may develop chronically over time [24] (Fig. 5).

Pelvic endometriosis has been described in adolescent girls prior to menarche and coelomic metaplasia had been 


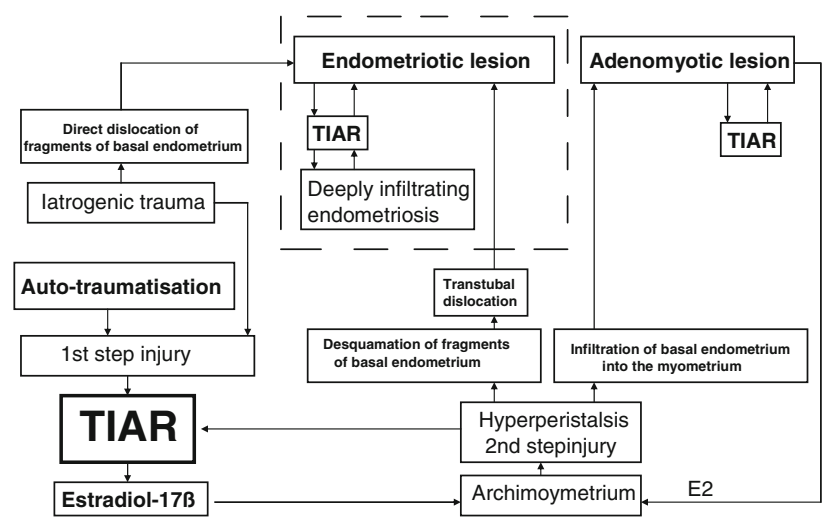

Fig. 5 Model of the pathophysiology of endometriosis and adenomyosis. Tissue injury in the depth of the endometrium and the activation of the TIAR system constitute the primum movens in the disease development. This pertains to spontaneously developing andometriosis/ adenomyosis as well as to that induced by iatrogenic trauma. The dashed rectangle depicts the extra uterine sites of the disease process

suggested as the underlying mechanism [70]. Large antral follicles are observed in the ovaries of premenarcheal girls that might stimulate uterine peristalsis [71]. Thus, detachment and upward transport of fragments of basal endometrium from the more or less unstimulated endometrium in these girls has to be considered as well.

In this respect, the significance of menstruation in the disease process [72] should be more precisely defined. During menstruation the basal endometrium is maximally exposed. This facilitates, in the presence of hyperperistalsis, both, the detachment of fragments of basal endometrium and their upward transport [21, 29, 33].

\section{Iatrogenic injury}

Iatrogenic traumata to the uterus are considered to increase the risk for the development of endometriosis and adenomyosis [73]. A history of hysterotomy in colonized rhesus monkeys showed a significant association with the later development of endometriosis in these animals [67]. The underlying mechanism of induction of endometriosis by iatrogenic trauma such as curettage and other ablative techniques appears to be very similar to those described above. Such surgical interventions might result in extended lesions with an enhanced TIAR reaction. The rapidly increasing local estrogen levels during the process of healing interfere with the ovarian control over uterine peristaltic activity leading rapidly to second step injury with ensuing auto-traumatization and perpetuation of the disease process. Thus, within the context of our model, iatrogenic lesions that result in the development of endometriosis and adenomyosis can be viewed as strong one-time 'first-step' injuries. In the baboon model experimental endometriosis was induced by inoculation of endometrial fragments that were obtained by endometrial biopsies during the menstrual phase of the animals. In the endometriotic lesions Cyr61, a highly estrogen dependent gene, was soon up-regulated [43]. Surprisingly, Cyr61 started to be up-regulated also in the eutopic endometrium of these primarily healthy animals. Most probably, the activation of Cyr61 in the eutopic endometrium resulted from the activation of the TIAR system with local production of estrogen following tissue injury that was caused by the biopsy rather than from a 'cross-talk' between the endometriotic lesions and the eutopic endometrium as suggested by the authors.

The eutopic endometrium in endometriosis and the endometriotic lesions

In both, the endometriotic lesions and in the eutopic endometrium of women with endometriosis, the cellular and molecular components of the regulatory systems that enable the tissue to produce estradiol have been demonstrated to be expressed. While this has been convincingly shown for peritoneal lesions, data concerning the eutopic endometrium of women with endometriosis are unequivocal in this respect.

Fragments of basal endometrium constitute injured tissue. The expression of acute and inflammatory cytokines such as interleukin- $1 \beta$ and interleukin 6 and also interleukin-8 [65, 74] facilitate implantation. As auto-transplants, however, the fragments should implant without inflammatory sequels. Due to the cyclic strain imposed upon the peritoneal endometriotic lesions the TIAR system is repeatedly and chronically activated. Immunohistochemistry has demonstrated also a dramatic up-regulation of the estradiol receptor alpha [21]. In superficial lesions this chronic inflammatory process might calm down and healing might be possible [75]. Deeply infiltrating lesions develop at sites that are in addition subjected to chronic mechanical irritation such as the recto-sigmoid fixed to the pelvic wall or uterus, the sacro-uterine ligaments, the urinary bladder, ovaries fixed to the pelvic wall, the recto-vaginal septum as well as the abdominal wall. It appears that chronic trauma to the ectopic lesions maintains the inflammatory process and results in the same tissue response as seen in uterine adenomyosis [3]. These are in fact the extra-uterine sites of adenomyoma described by Cullen [76].

As delineated above, the disease process starts focally in the depth of the basal endometrium. Thus, endometrial biopsies might miss the focus with an activated TIAR system. With the progression of the disease the area of alteration might be expanded. This is in keeping with the observation that the molecular markers associated with endometriosis could be more consistently demonstrated in more advanced stages of the disease [40]. 
With respect to the molecular biology of the eutopic endometrium in endometriosis it has to be taken into consideration that the endometrium is composed morphologically and functionally of at least two distinct layers, the basalis and the functionalis layers, respectively [21, 77-79]. This is not sufficiently taken into account when studies on molecular biology are performed with material taken from more or less random endometrial biopsies [39-41, 80]. The basal endometrium in women with endometriosis is twice as thick as in healthy women [21,33]. Moreover, while in healthy women the endometrial-myometrial lining is smooth and regular it is irregular and sometimes polypoid in affected women [3, 81]. Thus, biopsies taken from women with endometriosis might to a variable and unknown extent, be 'contaminated' with basal endometrium. This might explain at least in part the finding of 'progesterone resistance' [40, 82, 83], and an impaired estradiol metabolism in the endometrium of women with endometriosis [41, 80]. Using immunohistochemistry of estradiol receptor alpha and progesterone receptor no progesterone resistance could be observed in the late secretory phase of the functional endometrium of affected women. As in healthy women, with the progression of the secretory phase, the ER and PR expression declined in the functionalis and steadily rose in the basalis as well as in the endometriotic lesions [21]. The latter findings suggest physiological progesterone resistance in the basal endometrium and also in the endometriotic lesions as they are derived from implanted fragments of basal endometrium. Moreover, clinical studies with oocyte donation do not support a generally impeded implantation in women with endometriosis [84]. With respect to the expression of the $17 \beta$ HSD type 2 no data are available that distinguish between functionalis and basalis $[83,85]$.

\section{Conclusions}

Both, endometriosis and adenomyosis may now be integrated into the physiological mechanism and new nosological concept of "tissue injury and repair" (TIAR) and may, in this context, represent the extreme of a basically physiological, estrogen-related mechanism that is pathologically exaggerated in an extremely estrogen-sensitive, reproductive organ.

Circumstantial evidence suggests that endometriosis and adenomyosis are caused by trauma. In the spontaneously developing disease, chronic uterine peristaltic activity or phases of hyperperistalsis induce, at the endometrial-myometrial interface near the fundo-cornual raphe, microtraumatizations with the activation of the TIAR mechanism. This results in the local production of estrogen. With ongoing peristaltic activity, such sites might increase and the increasingly produced estrogens would interfere in a paracrine fashion with the ovarian control over uterine peristaltic activity, resulting in permanent hyperperistalsis and a self-perpetuation of the disease process. Overt autotraumatization of the uterus with dislocation of fragments of the basal endometrium into the peritoneal cavity and infiltration of the basal endometrium into the depth of the myometrial wall ensues. In most cases of endometriosis/ adenomyosis, a causal event early in the reproductive period of life must be postulated leading rapidly to uterine hyperperistalsis. In late premenopausal adenomyosis, such an event might not have occurred. However, as indicated by the high prevalence of the disease, it appears to be unavoidable that, with time, chronic normoperistalsis throughout the reproductive period of life leads to the same kind of microtraumatization. With the activation of the TIAR mechanism, followed by chronic inflammation [86] and infiltrative growth, endometriosis/adenomyosis of the younger woman and premenopausal adenomyosis share in principle the same pathophysiology. In conclusion, endometriosis and adenomyosis result from the exaggeration of the basically physiological mechanism of 'tissue injury and repair' (TIAR) involving local estrogen production. This is further magnified in an estrogen-sensitive environment normally controlled by the ovary.

Conflict of interest statement No Conflict of interest statement was provided by the authors.

Open Access This article is distributed under the terms of the Creative Commons Attribution Noncommercial License which permits any noncommercial use, distribution, and reproduction in any medium, provided the original author(s) and source are credited.

\section{References}

1. Greene R, Stratton P, Cleary SD, Ballweg ML, Sinaii N (2009) Diagnostic experience among 4,334 women reporting surgically diagnosed endometriosis. Fertil Steril 91:32-39

2. Moen MH, Muus KM (1991) Endometriosis in pregnant and nonpregnant women at tubal sterilisation. Hum Reprod 6:699-702

3. Leyendecker G, Kunz G, Kissler S, Wildt L (2006) Adenomyosis and reproduction. Best Pract Res Clin Obstet Gynaecol 20:523-546

4. Leyendecker G, Kunz G, Noe M, Herbertz M, Mall G (1998) Endometriosis: a dysfunction and disease of the archimetra. Hum Reprod Update 4:752-762

5. Donnez O, Jadoul P, Squifflet J, Donnez J (2006) Iatrogenic peritoneal adenomyoma after laparoscopic subtotal hysterectomy and uterine morcellation. Fertil Steril 86:1511-1512

6. Koninckx PR, Braet P, Kennedy SH, Barlow DH (1994) Dioxin pollution and endometriosis in Belgium. Hum Reprod 9:10011002

7. Parazzini F, Chiaffarino F, Surace M, Chatenoud L, Cipriani S, Chiantera V, Benzi G, Fedele L (2004) Selected food intake and risk of endometriosis. Hum Reprod 19:1755-1759

8. Montgomery GW, Nyholt DR, Zhao ZZ, Treloar SA, Painter JN, Missmer SA, Kennedy SH, Zondervan KT (2008) The search for 
genes contributing to endometriosis risk. Hum Reprod Update $14: 447-457$

9. Werth R, Grusdew W (1898) Untersuchungen über die Entwicklung und Morphologie der menschlichen Uterusmuskulatur. Arch Gynäkol 55:325-409

10. Wetzstein R (1965) Der Uterusmuskel: Morphologie. Arch Gynecol 202:1-13

11. Noe M, Kunz G, Herbertz M, Mall G, Leyendecker G (1999) The cyclic pattern of the immunocytochemical expression of oestrogen and progesterone receptors in human myometrial and endometrial layers: characterisation of the endometrial-subendometrial unit. Hum Reprod 14:101-110

12. De Vries K, Lyons EA, Ballard G, Levi CS, Lindsay DJ (1990) Contractions of the inner third of the myometrium. Am J Obstet Gynaecol 162:679-682

13. Lyons EA, Taylor PJ, Zheng XH, Ballard G, Levi CS, Kredentser JV (1991) Characterisation of subendometrial myometrial contractions throughout the menstrual cycle in normal fertile women. Fertil Steril 55:771-775

14. Williams M, Hill CJ, Scudamore I, Dunphy B, Cooke ID, Barratt CLR (1993) Sperm numbers and distribution within the human fallopian tube around ovulation. Hum Reprod 8:2019-2026

15. Kunz G, Beil D, Deininger H, Wildt L, Leyendecker G (1996) The dynamics of rapid sperm transport through the female genital tract. Evidence from vaginal sonography of uterine peristalsis (VSUP) and hysterosalpingoscintigraphy (HSSG). Hum Reprod 11:627632

16. Wildt L, Kissler S, Licht P, Becker W (1998) Sperm transport in the human female genital tract and its modulation by oxitocin as assessed by hystrosalpingography, hysterotonography, electrohysterography and Doppler sonography. Hum Reprod Update 4:655666

17. Schmiedehausen K, Kat S, Albert N, Platsch G, Wildt L, Kuwert $\mathrm{T}$ (2003) Determination of velocity of tubar transport with dynamic hysterosalpingoscintigraphy. Aug Nucl Med Commun 24:865870

18. Zervomanolakis I, Ott HW, Hadziomerovic D, Mattle V, Seeber BE, Virgolini I, Heute D, Kissler S, Leyendecker G, Wildt L (2007) Physiology of upward transport in the human female genital tract. Ann N Y Acad Sci 1101:1-20

19. Zervomanolakis I, Ott HW, Müller J, Seeber BE, Friess SC, Mattle V, Virgolini I, Heute D, Wildt L (2009) Uterine mechanisms of ipsilateral directed spermatozoa transport: evidence for a contribution of the utero-ovarian countercurrent system. Eur J Obstet Gynecol Reprod Biol 144(Suppl 1):S45-S49

20. Garcia-Segura LM (2008) Aromatase in the brain: not just for reproduction anymore. J Neuroendocrinol 20:705-712

21. Leyendecker G, Herbertz M, Kunz G, Mall G (2002) Endometriosis results from the dislocation of basal endometrium. Hum Reprod 17:2725-2736

22. Kunz G, Beil D, Huppert P, Leyendecker G (2000) Structural abnormalities of the uterine wall in women with endometriosis and infertility visualized by vaginal sonography and magnetic resonance imaging. Hum Reprod 15:76-82

23. Kunz G, Beil D, Huppert P, Noe M, Kissler S, Leyendecker G (2005) Adenomyosis in endometriosis-prevalence and impact on fertility. Evidence from magnetic resonance imaging. Hum Reprod 20:2309-2316

24. Kunz G, Herbertz M, Beil D, Huppert P, Leyendecker G (2007) Adenomyosis as a disorder of the early and late human reproductive period. Reprod Biomed Online 15:681-685

25. Dueholm M, Lundorf E, Hansen ES, Sørensen JS, Ledertoug S, Olesen F (2001) Magnetic resonance imaging and transvaginal ultrasonography for the diagnosis of adenomyosis. Fertil Steril 76:588-594
26. Barrier BF, Malinowski MJ, Dick EJ Jr, Hubbard GB, Bates GW (2004) Adenomyosis in the baboon is associated with primary infertility. Fertil Steril 82(Suppl 3):1091-1094

27. Mäkäräinen L (1988) Uterine contractions in endometriosis: effects of operative and danazol treatment. Obstet Gynecol 9:134-138

28. Salamanca A, Beltran E (1995) Subendometrial contractility in menstrual phase visualised by transvaginal sonography in patients with endometriosis. Fertl Steril 64:193-195

29. Leyendecker G, Kunz G, Wildt L, Beil D, Deininger H (1996) Uterine hyperperistalsis and dysperistalsis as dysfunctions of the mechanism of rapid sperm transport in patients with endometriosis and infertility. Hum Reprod 11:1542-1551

30. Bulletti C, De Ziegler D, Polli V, Del Ferro E, Palini S, Flamigni C (2002) Characteristics of uterine contractility during menses in women with mild to moderate endometriosis. Fertil Steril $77: 1156-1161$

31. Kissler S, Hamscho N, Zangos S, Wiegratz I, Schlichter S, Menzel C, Doebert N, Gruenwald F, Vogl TJ, Gaetje R, Rody A, Siebzehnruebl E, Kunz G, Leyendecker G, Kaufmann M (2006) Uterotubal transport disorder in adenomyosis and endometriosis-a cause for infertility. BJOG 113:902-908

32. Kissler S, Zangos S, Wiegratz I, Kohl J, Rody A, Gaetje R, Doebert N, Wildt L, Kunz G, Leyendecker G, Kaufmann M (2007) Utero-tubal sperm transport and its impairment in endometriosis and adenomyosis. Ann N Y Acad Sci 1101:38-48

33. Leyendecker G, Kunz G, Herbertz M, Beil D, Huppert P, Mall G, Kissler S, Noe M, Wildt L (2004) Uterine peristaltic activity and the development of endometriosis. Ann NY Acad Sci 1034:338-355

34. Takahashi K, Nagata H, Kitao M (1989) Clinical usefulness of determination of estradiol levels in the menstrual blood for patients with endometriosis. Acta Obstet Gynecol Jpn 41:1849-1850

35. Yamamoto T, Noguchi T, Tamura T, Kitiwaki J, Okada H (1993) Evidence for oestrogen synthesis in adenomyotic tissues. Am J Obstet Gynecol 169:734-738

36. Noble LS, Simpson ER, Johns A, Bulun SE (1996) Aromatas expression in endometriosis. J Clin Endocrinol Metab 81:174-179

37. Noble LS, Takayama K, Zeitoun KM, Putman JM, Johns DA, Hinshelwood MM, Agarwal VR, Zhao Y, Carr BR, Bulun SE (1997) Prostaglandin E2 stimulates aromatase expression in endometriosis-derived stromal cells. J Clin Endocrinol Metab 82:600-606

38. Kitawaki J, Noguchi T, Amatsu T, Maeda K, Tsukamoto K, Yamamoto T, Fushiki S, Osawa Y, Honjo H (1997) Expression of aromatase cytochrome $\mathrm{P} 450$ protein and messenger ribonucleic acid in human endometriotic and adenomyotic tissues but not in normal endometrium. Biol Reprod 57:514-519

39. Hudelist G, Czerwenka K, Keckstein J, Haas C, Fink-Retter A, Gschwantler-Kaulich D, Kubista E, Singer CF (2007) Expression of aromatase and estrogen sulfotransferase in eutopic and ectopic endometrium: evidence for unbalanced estradiol production in endometriosis. Reprod Sci 14:798-805

40. Aghajanova L, Hamilton A, Kwintkiewicz J, Vo KC, Giudice LC (2009) Steroidogenic enzyme and key decidualization marker dysregulation in endometrial stromal cells from women with versus without endometriosis. Biol Reprod 80:105-114

41. Bulun SE (2009) Endometriosis. N Engl J Med 360:268-279

42. Absenger Y, Hess-Stumpp H, Kreft B, Kratzschmar J, Haendler B, Schutze N, Regidor PA, Winterhager E (2004) Cyr61, a deregulated gene in endometriosis. Mol Hum Reprod 10:399-407

43. Gashaw I, Hastings JM, Jackson KS, Winterhager E, Fazleabas AT (2006) Induced endometriosis in the baboon (Papio anubis) increases the expression of the proangiogenic factor CYR61 (CCN1) in eutopic and ectopic endometria. Biol Reprod 74:1060 1066

44. Kunz G, Noe M, Herbertz M, Leyendecker G (1998) Uterine peristalsis during the follicular phase of the menstrual cycle. Effects of 
oestrogen, antioestrogen and oxytocin. Hum Reprod Update 4:647-654

45. Leyendecker G (2000) Endometriosis is an entity with extreme pleiomorphism. Hum Reprod 15:4-7

46. D'Hooghe TM, Bambra CS, Raeymaekers BM, De Jonge I, Lauweryns JM, Koninckx PR (1995) Intrapelvic injection of menstrual endometrium causes endometriosis in baboons (Papio cynocephalus and Papio anubis). Am J Obstet Gynecol 173:125134

47. Fazleabas AT, Brudney A, Chai D, Langoi D, Bulun SE (2003) Steroid receptor and aromatase expression in baboon endometriotic lesions. Fertil Steril 80(Suppl 2):820-827

48. Nyachieo A, Chai DC, Deprest J, Mwenda JM, D'Hooghe TM (2007) The baboon as a research model for the study of endometrial biology, uterine receptivity and embryo implantation. Gynecol Obstet Invest 64:149-155

49. Ashcroft GS, Ashworth JJ (2003) Potential role of estrogens in wound healing. Am J Clin Dermatol 4:737-743

50. Gilliver SC, Ashworth JJ, Ashcroft GS (2007) The hormonal regulation of cutaneous wound healing. Clin Dermatol 25:56-62

51. Mowa CN, Hoch R, Montavon CL, Jesmin S, Hindman G, Hou G (2008) Estrogen enhances wound healing in the penis of rats. Biomed Res 29:267-270

52. Sierra A, Lavaque E, Perez-Martin M, Azcoitia I, Hales DB, Garcia-Segura LM (2003) Steroidogenic acute regulatory protein in the rat brain: cellular distribution, developmental regulation and overexpression after injury. Eur J Neurosci 18:1458-1467

53. Lavaque E, Sierra A, Azcoitia I, Garcia-Segura LM (2006) Steroidogenic acute regulatory protein in the brain. Neuroscience 138:741-747

54. Yang G, Im HJ, Wang JH (2005) Repetitive mechanical stretching modulates IL-1beta induced COX-2, MMP-1 expression, and PGE2 production in human patellar tendon fibroblasts. Gene 363:166-172

55. Jeffrey JE, Aspden RM (2007) Cyclooxygenase inhibition lowers prostaglandin E2 release from articular cartilage and reduces apoptosis but not proteoglycan degradation following an impact load in vitro. Arthritis Res Ther 9:R129

56. Shioyama R, Aoki Y, Ito H, Matsuta Y, Nagase K, Oyama N, Miwa Y, Akino H, Imamura Y, Yokoyama O (2008) Long-lasting breaches in the bladder epithelium lead to storage dysfunction with increase in bladder PGE2 levels in the rat. Am J Physiol Regul Integr Comp Physiol 295:R714-R718

57. Hadjiargyrou M, Ahrens W, Rubin CT (2000) Temporal expression of the chondrogenic and angiogenic growth factor CYR61 during fracture repair. J Bone Miner Res 15:1014-1023

58. Garcia-Segura LM, Wozniak A, Azcoitia I, Rodriguez JR, Hutchison RE, Hutchison AB (1999) Aromatase expression by astrocytes after brain injury: implications for local estrogen formation in brain repair. Neuroscience 89:567-578

59. Gurates B, Bulun SE (2003) Endometriosis: the ultimate hormonal disease. Semin Reprod Med 21:125-134

60. Kissler S, Schmidt M, Keller N, Wiegratz T, Tonn T, Roth KW, Seifried E, Baumann R, Siebzehnruebl E, Leyendecker G, Kaufmann M (2005) Real-time PCR analysis for estrogen receptor beta and progesterone receptor in menstrual blood samples-a new approach to a non-invasive diagnosis for endometriosis. Hum Reprod 20(suppl.):i179 (P-496)

61. Attar E, Bulun SE (2006) Aromatase and other steroidogenic genes in endometriosis: translational aspects. Hum Reprod Update 12:49-56

62. Attar E, Tokunaga H, Imir G, Yilmaz MB, Redwine D, Putman M, Gurates B, Attar R, Yaegashi N, Hales DB, Bulun SE (2009) Prostaglandin E2 via steroidogenic factor-1 coordinately regulates transcription of steroidogenic genes necessary for estrogen synthesis in endometriosis. J Clin Endocrinol Metab 94:623-631
63. Kunz G, Herbertz M, Noe M, Leyendecker G (1998) Sonographic evidence of a direct impact of the ovarian dominant structure on uterine function during the menstrual cycle. Hum Reprod Update 4:667-672

64. Kunz G, Kissler S, Wildt L, Leyendecker G (2000) Uterine peristalsis: directed sperm transport and fundal implantation of the blastocyst. In: Filicori M (ed) Endocrine basis of reproductive function. Monduzzi Editore, Bologna, Italy

65. Harada M, Osuga Y, Hirota Y, Koga K, Morimoto C, Hirata T, Yoshino O, Tsutsumi O, Yano T, Taketani Y (2005) Mechanical stretch stimulates interleukin-8 production in endometrial stromal cells: possible implications in endometrium-related events. J Clin Endocrinol Metab 90(2):1144-1148

66. Mahmood TA, Templeton A (1990) Pathophysiology of mild endometriosis: review of literature. Hum Reprod 5:765-784

67. Hadfield RM, Yudkin PL, Coe CL, Scheffler J, Uno H, Barlow DH, Kemnitz JW, Kennedy SH (1997) Risk factors for endometriosis in the rhesus monkey (Macaca mulatta): a case-control study. Hum Reprod Update 3:109-115

68. Zingg HH, Rosen F, Chu K, Larcher A, Arslan AM, Richard S, Lefebvre D (1995) Oxytocin and oxytocin receptor gene expression in the uterus. Recent Progr Hormone Res 50:255-273

69. Mitzumoto Y, Furuya K, Makimura N, Mitsui C, Seki K, Kimura T, Nagata I (1995) Gene expression of oxytocin receptor in human eutopic endometrial tissues. Adv Exp Med Biol 395:491-493

70. Marsh EE, Laufer MR (2005) Endometriosis in premenarcheal girls who do not have an obstructive anomaly. Fertil Steril 83:758760

71. Peters H (1977) The human ovary in childhood and early maturity. Eur J Obstet Gynec Reprod Biol 9:137-144

72. Sampson JA (1927) Peritoneal endometriosis due to the menstrual dissemination of endometrial tissue into the peritoneal cavity. Am J Obstet Gynaecol 14:422-429

73. Counseller VS (1938) Endometriosis: a clinical and surgical review. Am J Obstet Gynecol 36:877-886

74. Tseng JF, Ryan IP, Milam TD, Murai JT, Schriock ED, Landers DV, Taylor RN (1996) Interleukin-6 secretion in vitro is up-regulated in ectopic and eutopic endometrial stromal cells from women with endometriosis. J Clin Endocrinol Metab 81:1118-1122

75. Vercellini P, Aimi G, Panazza S, Vicentini S, Pisacreta A, Crosignani PG (2000) Deep endometriosis conundrum: evidence in favor of a peritoneal origin. Fertil Steril 73:1043-1046

76. Cullen TS (1920) The distribution of adenomyoma containing uterine mucosa. Arch Surgery 1:215-283

77. Kaiserman-Abramof IR, Padykula HA (1989) Ultrastructural epithelial zonation of the primate endometrium (rhesus monkey). Am J Anat 184:13-30

78. Padykula HA, Coles LG, Okulicz WC, Rapaport SI, Mc Cracken JA, King NW Jr, Longcope C, Kaiserman-Abramof IR (1989) The basalis of the primate endometrium: a bifunctional germinal compartment. Biol Reprod 40:681-690

79. Okulicz WC, Balsamo M, Tast J (1993) Progesterone regulation of endometrial estrogen receptor and cell proliferation during the late proliferative and secretory phase in artificial menstrual cycles in the rhesus monkey. Biol Reprod 49:24-32

80. Delvoux B, Groothuis P, D’Hooghe T, Kyama C, Dunselman G, Romano A (2009) Increased production of 17beta-estradiol in endometriosis lesions is the result of impaired metabolism. J Clin Endocrinol Metab 94:876-883

81. McBean JH, Gibson M, Brumsted JR (1996) The association of intrauterine filling defects on hysterosalpingogram with endometriosis. Fertil Steril 66:522-526

82. Bulun SE, Cheng YH, Yin P, Imir G, Utsunomiya H, Attar E, Innes J, Julie Kim J (2006) Progesterone resistance in endometriosis: link to failure to metabolize estradiol. Mol Cell Endocrinol 248:94-103 
83. Burney RO, Talbi S, Hamilton AE, Vo KC, Nyegaard M, Nezhat CR, Lessey BA, Giudice LC (2007) Gene expression analysis of endometrium reveals progesterone resistance and candidate susceptibility genes in women with endometriosis. Endocrinology 148:3814-3826

84. Simon C, Gutierrez A, Vidal A, de los Santos MJ, Tarin JJ, Remohi J, Pellicer A (1994) Outcome of patients with endometriosis in assisted reproduction: results from in vitro fertilization and oocyte donation. Hum Reprod 9:725-729
85. Zeitoun K, Takayama K, Sasano H, Suzuki HAT, Moghrabi N, Andersson S, Johns A, Meng L, Putman M, Carr B et al (1998) Deficient $17 \beta$-hydroxysteroid dehydrogenase type 2 expression in endometriosis: failure to metabolize $17 \beta$-estradiol. J Clin Endocrinol Metab 83:4474-4480

86. Meyer R (1919) Über den Stand der Frage der Adenomyositis und Adenome im allgemeinen und insbesondere über Adenomyositis seroepithelialis und Adenomyometritis sarcomatosa. Zbl Gynäkol 43:745-750 